\title{
PENGARUH PENAMBAHAN FLY ASH DAN KONDISI ADUKAN TANAH LIAT TERHADAP KUAT TEKAN BATA MERAH
}

\author{
Nelly Astriani ${ }^{1)}$, Elhusna ${ }^{2)}$, Ade Sri Wahyuni ${ }^{3)}$ \\ ${ }^{122) 3)}$ Program Studi Teknik Sipil, Fakultas Teknik UNIB, Jl. W. R. Supratman, \\ Kandang Limun, Bengkulu 38371, Telp. (0736)344087 \\ email: inersia@unib.ac.id
}

\begin{abstract}
Abstrak
Artikel ini memaparkan hasil penelitian tentang pengaruh penambahan fly ash dan kadar air pada tanah liat terhadap kuat tekan bata merah. Pengujian sifat fisis dan kuat tekan bata merah mengacu pada SNI 15-2094-2000. Variasi fly ash yang digunakan adalah 5\%, 10\%, 15\%, 20\%, $25 \%$, dan 30\% dari berat tanah liat. Penambahan kadar air berdasarkan 3 kriteria kondisi adukan tanah liat yaitu keras, normal, dan lembek. Adukan keras adalah kondisi adukan pembentuk bata dengan penggunaan air yang kurang dari adukan normal. Adukan normal adalah kondisi adukan pembentuk bata dengan penggunaan air berdasarkan takaran yang biasa dikerjakan di pabrik bata. Adukan lembek adalah kondisi adukan pembentuk bata dengan penggunaan air yang lebih banyak dari adukan normal. Benda uji pada penelitian ini dibuat sebanyak 8 benda uji untuk bata normal dan 144 benda uji untuk bata variasi. Kuat tekan bata variasi adukan keras dan normal pada variasi $10 \%$ meningkat sebesar $35,59 \%$, dan $2,82 \%$ dari bata normal. Kuat tekan bata variasi adukan lembek pada variasi $5 \%$ meningkat sebesar $28,25 \%$ dari bata normal.
\end{abstract}

Kata kunci: bata, fly ash, kadar air, kuat tekan

\begin{abstract}
This article describes the research result of the effect of adding fly ash and water concentration of clay on red bricks' compressive strength. Fisis characteristic and bricks' compressive strength is according to SNI 15-2094-2000. Variation of fly ash that were used were 5\%, 10\%, $15 \%, 20 \%, 25 \%$, and 30\% from the weight of clay. Adding water concentration was based on three criterions of mortar clay condition, namely hard, normal, and soft. Hardmortar clayis a condition of the clay mixture which used less water than the normal mixture. Normal mixture is a condition ofthe clay mixture which usedwater based on usual concentration in brick factory. Soft mixture is a condition ofthe clay mixture that used much water than normal mixture. In this research, there are 8 sample for normal bricks and there are 144 sample for variation bricks. The optimum value of compressive strength for hard and normal mixture of variation bricks were obtained in $10 \%$ of fly ash variation which increased 33,59\%, and 2,82\% from normal bricks. Compressive strength for soft mixture of bricks was obtained in 5\% of fly ash variation which increased 28,25\% from normal bricks.
\end{abstract}

Keywords: brick, fly ash, water concentration, compressive strength 


\section{PENDAHULUAN}

Bata adalah bahan bangunan yang digunakan sebagai dinding yang merupakan bangunan non struktural yang tidak memikul beban secara langsung. Bata terbuat dari tanah liat dengan atau tanpa campuran bahan lain (SNI 15-2094-2000). Bata yang baik sebagian besar mengandung silika dan alumina (Suseno, dkk, 2012).

Tanah liat merupakan bahan baku dari proses pembuatan bata, dimana kegunaannya sangat menguntungkan bagi manusia karena bahan baku dari bata yang mudah didapatkan. Tanah liat memiliki beberapa sifat yang khas yaitu bila dalam keadaan basah mempunyai sifat plastis tetapi bila dalam keadaan kering menjadi keras, sedangkan bila dibakar menjadi kuat dan padat. Tanah liat sebelum dibuat bata harus dicampur secara merata yang disebut dengan pekerjaan pelumatan dengan menambahkan sedikit air (Huda dan Hastuti, 2012).

Pembuatan bata memerlukan bahan air, agar tanah liat mempunyai sifat plastis yang sangat diperlukan dalam pembentukannya. Air merupakan cairan jernih yang tidak berbau, tidak berwarna serta mengandung hidrogen dan oksigen didalamnya (Dinata, dkk, 2013).

Meningkatnya kebutuhan masyarakat akan bahan bangunan seperti bata harus diiringi dengan persediaan bata yang mencukupi dan juga berkualitas, oleh sebab itu dibutuhkan alternatif yang dapat meningkatkan kualitas bata. Salah satu hal yang dapat dilakukan dalam meningkatkan kualitas bata merah adalah dengan menambahkan bahan campuran ke dalam komposisi pembuatan bata merah (Dinata, dkk, 2013).

Pemanfaatan limbah seperti fly ash perlu dipertimbangkan sebagai bahan campuran bata, karena dapat meningkatkan kuat tekan bata dan memperkecil rongga-rongga pori pada bata. Campuran yang digunakan dalam penelitian ini adalah abu sisa pembakaran batu bara (fly ash).

Fly ash merupakan residu mineral dalam butir halus yang dihasilkan dari pembakaran batu bara yang dihaluskan pada suatu pusat pembangkit listrik. Fly ash mengandung unsur kimia antara lain silika $\left(\mathrm{SiO}_{2}\right)$, alumina $\left(\mathrm{Al}_{2} \mathrm{O}_{3}\right)$, fero oksida $\left(\mathrm{Fe}_{2} \mathrm{O}_{3}\right)$ dan kalsium oksida $(\mathrm{CaO})$ (Abdurrohmansyah, dkk, 2015).

Sifat- sifat kimia yang dimiliki fly ash dan tanah liat memiliki kesamaan yaitu silika dan alumina yang apabila bereaksi dengan kalsium oksida yang terkandung dalam tanah liat dapat membentuk senyawa stabil yang mempunyai sifat mengikat (Huda dan Hastuti, 2012).

Pemanfaatan limbah hasil pembakaran batu bara (fly ash) sebagai bahan campuran bata merah dan untuk mengetahui pengaruh penambahan fly ash pada kuat tekan bata merah pada kondisi adukan tanah liat yang berbeda. Fly ash yang ditambahkan adalah $5 \%, 10 \%, 15 \%, 20 \%, 25 \%$, dan $30 \%$ dari berat tanah liat.

\section{METODE PENELITIAN}

Variasi fly ash yang ditambahkan adalah $5 \%, 10 \%, 15 \%, 20 \%, 25 \%$, dan $30 \%$ dari berat tanah liat. Penelitian ini menggunakan 3 kriteria kondisi adukan yaitu keras, normal dan lembek. Adukan keras adalah kondisi adukan pembentuk bata dengan penggunaan air minimal yang masih memungkinkan bata untuk dicetak. Adukan normal adalah kondisi adukan pembentuk bata dengan penggunaan air berdasarkan takaran yang biasa dikerjakan di pabrik bata. Adukan lembek adalah kondisi adukan pembentuk bata dengan penggunaan air maksimal yang masih memungkinkan bata untuk dicetak. Komposisi bahan yang digunakan dapat dilihat pada Tabel 1. 
Tabel 1. Komposisi Bahan

\begin{tabular}{|c|c|c|}
\hline \multirow{2}{*}{ Variasi } & \multicolumn{2}{|c|}{ Berat (kg) } \\
\cline { 2 - 3 } & Tanah Liat & Fly Ash \\
\hline $0 \%$ & 22,5 & - \\
\hline $5 \%$ & 22,5 & 1,125 \\
\hline $10 \%$ & 22,5 & 2,25 \\
\hline $15 \%$ & 22,5 & 3,375 \\
\hline $20 \%$ & 22,5 & 4,5 \\
\hline $25 \%$ & 22,5 & 5,625 \\
\hline $30 \%$ & 22,5 & 6,75 \\
\hline
\end{tabular}

\section{Tanah liat}

Tanah liat yang digunakan berasal dari lokasi pabrik. Sifat fisis tanah liat dapat dilihat pada Tabel 2.

Tabel 2. Sifat Fisis Tanah Liat

\begin{tabular}{|l|c|}
\hline \multicolumn{1}{|c|}{ Uraian } & NilaiPemeriksaan \\
\hline Berat Isi & $1,27 \mathrm{gr} / \mathrm{cm}^{3}$ \\
\hline Berat Jenis & $2,76 \mathrm{gr} / \mathrm{cm}^{3}$ \\
\hline Kadar Air & $46,20 \%$ \\
\hline Hidrometri & $72,060 \%$ \\
& $19,551 \%$ \\
\hline Atterberg Limit & \\
Batas Cair (LL) & $61,83 \%$ \\
Batas Plastis (PL) & $47,17 \%$ \\
IndeksPlastisitas & \\
(PI) & $14,65 \%$ \\
\hline
\end{tabular}

\section{Fly ash}

Fly ash yang digunakan adalah yang lolos saringan No. 100. Fly ash berasal dari hasil pembakaran batu bara di PT. Priamanaya Energi PLTU Keban Agung Kabupaten Lahat, Provinsi Sumatera Selatan. Sifat fisis fly ash dapat dilihat pada Tabel 3.

Tabel 3. Sifat Fisis Fly Ash

\begin{tabular}{|l|c|}
\hline \multicolumn{1}{|c|}{ Uraian } & Nilai Pemeriksaan \\
\hline Berat Isi & $0,99 \mathrm{gr} / \mathrm{cm}^{3}$ \\
\hline Kadar Air & $2,88 \%$ \\
\hline Berat Jenis & $2,13 \mathrm{gr} / \mathrm{cm}^{3}$ \\
\hline
\end{tabular}

\section{Adukan tanah liat}

Sifat fisis adukan tanah liat pada penelitian ini dapat dilihat pada Tabel 4.
Tabel 4. Sifat Fisis Adukan Tanah Liat

\begin{tabular}{|c|c|c|c|c|c|c|}
\hline \multirow{2}{*}{$\begin{array}{l}\text { Fly } \\
\text { Ash }\end{array}$} & \multicolumn{2}{|c|}{$\begin{array}{c}\text { Adukan } \\
\text { Keras }\end{array}$} & \multicolumn{2}{|c|}{$\begin{array}{l}\text { Adukan } \\
\text { Normal }\end{array}$} & \multicolumn{2}{|c|}{$\begin{array}{l}\text { Adukan } \\
\text { Lembek }\end{array}$} \\
\hline & $\begin{array}{c}\text { Berat } \\
\text { Isi }\end{array}$ & $\begin{array}{c}\text { Kadar } \\
\text { Air } \\
(\%)\end{array}$ & $\begin{array}{c}\text { Berat } \\
\text { Isi }\end{array}$ & $\begin{array}{c}\text { Kadar } \\
\text { Air } \\
(\%)\end{array}$ & $\begin{array}{c}\text { Berat } \\
\text { Isi }\end{array}$ & $\begin{array}{c}\text { Kadar } \\
\text { Air } \\
(\%)\end{array}$ \\
\hline $0 \%$ & & 57 & 1,18 & 61 & & 64 \\
\hline $5 \%$ & & 49, & 1,49 & & 47 & 53,8 \\
\hline $10 \%$ & & $J 1$, & & J & .50 & 61,29 \\
\hline $5 \%$ & & 53,85 & & 7 & 52 & 63,93 \\
\hline $20 \%$ & & 58, & 1,56 & 3 & 54 & 66,67 \\
\hline $25 \%$ & 4 & 61,29 & 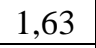 & 69,49 & 1,61 & 72,41 \\
\hline $0 \%$ & 70 & 66,67 & 1.69 & 72,41 & 1,68 & 75,4 \\
\hline
\end{tabular}

\section{Tahapan pengujian bata merah}

Tahapan pengujian bata merah dibedakan menjadi dua tahap yaitu pengujian fisis dan mekanis bata merahdengan mengacu pada SNI 15-2094-2000. Pengujian fisis bata merah pada penelitian ini yaitu pemeriksaan warna bata, pengukuran dimensi bata, dan pemeriksaan tekstur bata. Pengujian mekanis bata merah pada penelitian ini yaitu pengujian kuat tekan.

\section{HASIL DAN PEMBAHASAN}

\section{Warna dan tekstur bata merah}

Warna bata semua variasi adalah oranye kecoklatan dengan tekstur permukaan bata rata-rata kasar dan bentuknya kurang siku.

\section{Dimensi bata merah}

Dimensi bata merah pada penelitian ini tidak memenuhi standar yang disyaratkan oleh SNI 15-2094-2000 karena ukuran cetakan bata yang digunakan lebih kecil dari yang diisyaratkan SNI 15-2094-2000.

\section{Kuat tekan bata merah}

Gambar 1 memperlihatkan bahwa nilai kuat tekan terbesar pada adukan keras terjadi pada variasi fly ash $10 \%$ dengan nilai kuat tekan sebesar 4,80 MPa.Nilai kuat tekan bata merah tertinggi pada adukan normal terjadi pada variasi fly ash $10 \%$ dengan nilai kuat tekan rata-rata sebesar 3,64 $\mathrm{MPa}$ 
(Gambar 2). Nilai kuat tekan bata merah tertinggi pada adukan lembek terjadi pada variasi fly ash 5\% dengan nilai kuat tekan rata-rata sebesar 4,54 MPa (Gambar 3).

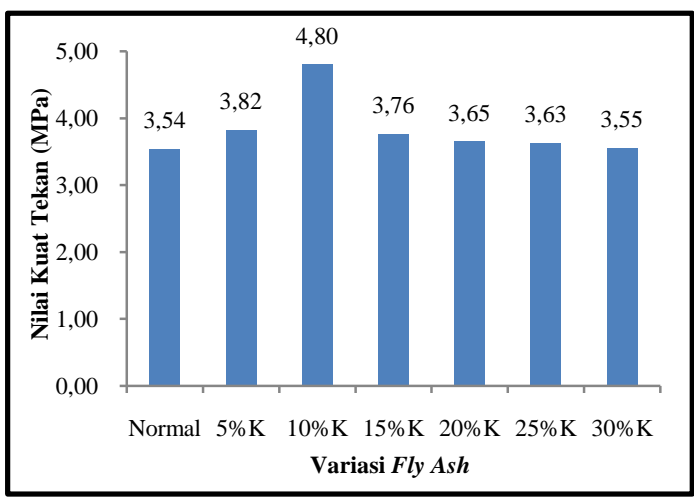

Gambar 1. Grafik Kuat Tekan Bata Merah

Adukan Keras

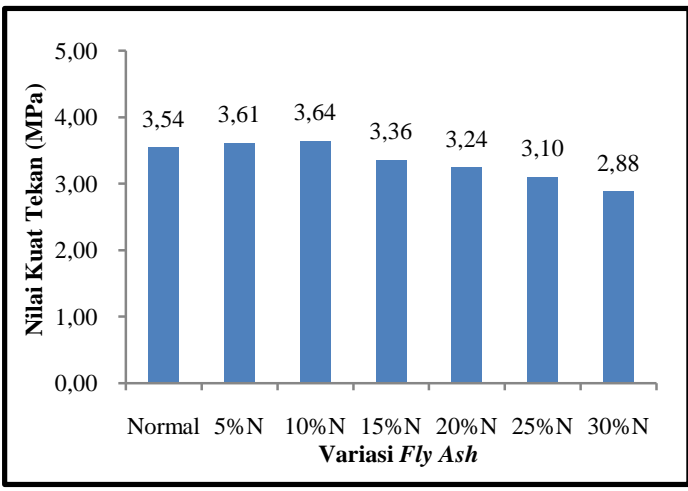

Gambar 2. Grafik Kuat Tekan Bata Merah Adukan Normal

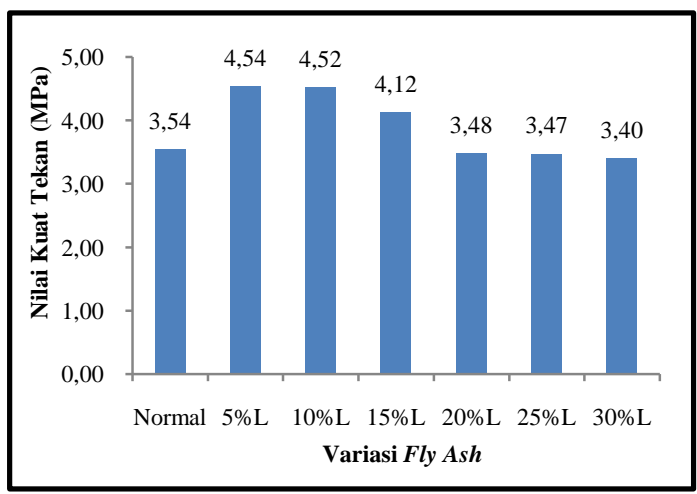

Gambar 3. Grafik Kuat Tekan Bata Merah Adukan Lembek

Nilai kuat tekan bata merah variasi fly ash dengan keadaan adukan keras, normal, dan lembek ini mengalami peningkatan dan penurunan dibandingkan dengan kuat tekan bata merah normal. Peningkatan dan penurunan kuat tekan tersebut dapat dilihat pada Gambar 4.

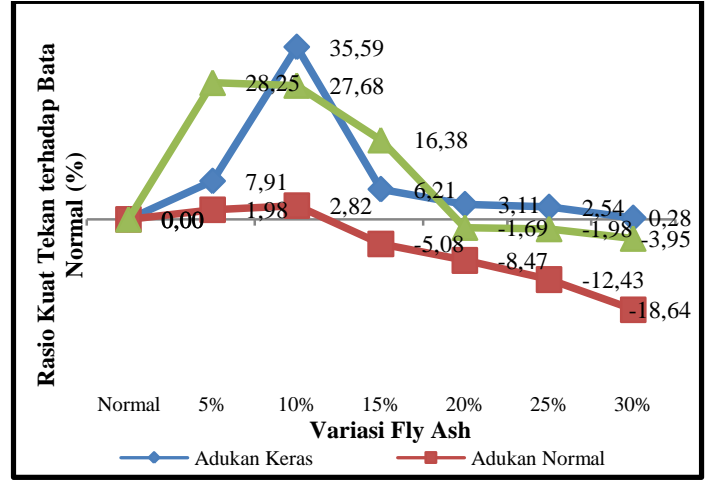

Gambar 4. Grafik Rasio Kuat Tekan Bata Variasi terhadap Bata Normal

Gambar 4 memperlihatkan bahwa pada adukan keras terjadi peningkatan kuat tekan yang paling tinggi di variasi $10 \%$ dan mengalami penurunan di $15 \%$ sampai $30 \%$ namun tetap lebih besar dari bata normal. Kuat tekan optimum pada adukan normal terjadi pada variasi $10 \%$ dan mengalami penurunan di $15 \%$ sampai $30 \%$ dari bata normal. Kuat tekan optimum pada adukan lembek terjadi pada variasi $5 \%$ dan mengalami penurunan di $20 \%$ sampai $30 \%$ dari bata normal.

Peningkatan kuat tekan bata adukan keras terjadi pada variasi $10 \%$ dikarenakan pada persentase variasi yang kecil dan penggunaan air yang sedikit membuat bata memiliki kandungan silika yang tidak berlebihan dan rongga pori bata berkurang, sehingga kekuatan bata meningkat. Peningkatan kuat tekan bata adukan lembek terjadi pada variasi 5\% dikarenakan pada persentase variasi yang kecil membuat bata memiliki kandungan silika yang tidak berlebihan akan tetapi rongga pori bata bertambah akibat penggunakan air yang banyak.

Penurunan kuat tekan bata adukan normal dan adukan lembek dikarenakan semakin besar persentase variasi fly ash maka semakin banyak pula kebutuhan air adukan bata yang diperlukan. Hal tersebut mengakibatkan rongga pori bata bertambah dan kekuatan bata menjadi menurun. Perbedaan rongga pori bata adukan keras 
dengan adukan lembek dapat dilihat pada Gambar 5.

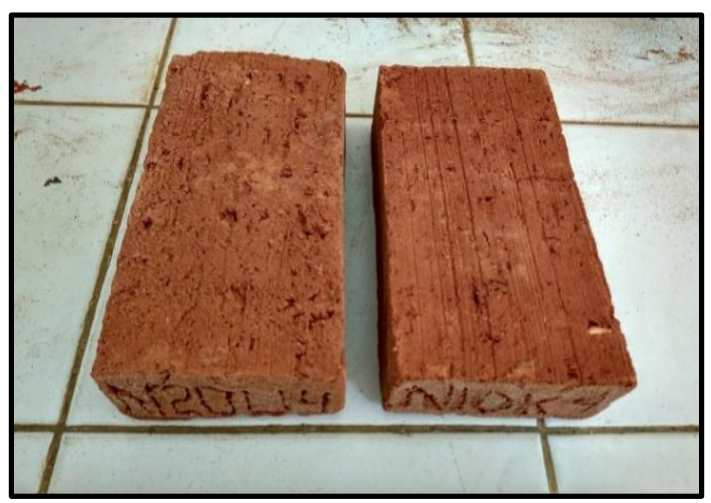

Gambar 5. Perbedaan Rongga Pori Bata Adukan Keras dan Lembek

\section{KESIMPULAN}

Kesimpulan dari penelitian ini adalah sebagai berikut:

1. Kuat tekan tertinggi bata adukan keras dan normal terjadi pada variasi fly ash $10 \%$. Kuat tekan tertinggi bata adukan lembek terjadi pada persentase variasi fly ash 5\%.

2. Persentase variasi fly ash yang kecil dan penggunaan air yang sedikit mampu meningkatkan kekuatan bata.

3. Penurunan kuat tekan yang terjadi disebabkan oleh persentase variasi fly ash yang besar dan penggunaan air yang banyak.

4. Semakin besar persentase variasi fly ash maka semakin banyak pula kebutuhan air adukan bata yang diperlukan, sehingga hal tersebut mengakibatkan rongga-rongga pori bata bertambah dan kekuatan bata menjadi menurun.

Parameter kondisi adukan keras dan lembek berdasarkan $50 \%$ dari kondisi adukan normal dan melakukan pemeriksaan indeks plastisitas pada adukan tanah liat perlu dilakukan untuk penelitian selanjutnya.

\section{DAFTAR PUSTAKA}

Abdurrohmansyah, Adha, I., dan Ali, H. 2015. Studi Kuat Tekan Batu Bata menggunakan Bahan Additive (Abu Sekam Padi, Abu Ampas Tebu dan Fly Ash) Berdasarkan Spesifikasi Standar Nasional Indonesia (SNI), JRSDD Vol.3. No.3. Jurusan Teknik Sipil. Fakultas Teknik. Universitas Lampung.

Dinata, M. T., Adha, I., dan Setyanto. 2013. Studi Pengaruh Lama Waktu Proses Pembakaran terhadap Kuat Tekan Batu Bata setelah Penambahan Bahan Additive ISS 2500 (Ionic Soil Stabilizer). JRSDD Vol.1. No.1. Jurusan Teknik Sipil. Fakultas Teknik. Universitas Lampung.

Huda, M., dan Hastuti, E. 2012. Pengaruh Temperatur Pembakaran dan Penambahan Abu terhadap Kualitas Batu Bata. Jurnal Neutrino Vol.4. No.2. Jurusan Fisika. Fakultas Sains dan Teknologi. UIN Maliki, Malang.

SNI 15-2094-2000. Bata Merah Pejal untuk Pasangan Dinding. BSN.

Suseno, H., Prastumi., Susanti, L., dan Setyowulan, D. 2012. Pengaruh Penggunaan Bottom Ash sebagai Pengganti Tanah Liat pada Campuran Bata terhadap Kuat Tekan Bata. Jurnal Rekayasa Sipil Vol.6. No.3. Jurusan Teknik Sipil. Fakultas Teknik. Universitas Brawijaya, Malang. 
ISSN 2086-9045 